Daimon. Revista Internacional de Filosofía, n ${ }^{\circ} 77,2019$, pp. 197-212

ISSN: 1130-0507 (papel) y 1989-4651 (electrónico)

http://dx.doi.org/10.6018/daimon/301601

\title{
Hermenéutica de la «semnótes»: el concepto de decoro en la ética de Aristóteles
}

\author{
Hermeneutic of the «Semnótes»: \\ The Decorum Concept in Aristotle's Ethics
}

DAVID HERNÁNDEZ CASTRO*

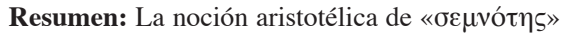
ha sido traducida generalmente por «dignidad», y los estados que flanquean a este modo de ser por

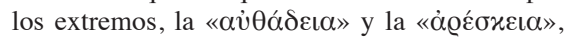
como «arrogancia»y «servilismo». En este artículo aporto argumentos para sostener que, en rea-

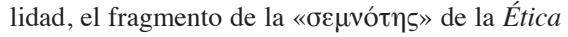
Eudemia mostraba una teoría del «decoro», cuyo defecto era la «grosería», y su exceso, la «obsequiosidad». El decoro de Aristóteles no equivalía al «decorum» de Cicerón, pero sí a la expresión «guardar el decoro» que cristalizó en el Siglo de Oro español.
\end{abstract}

Palabras clave: «aréskeia», «authádeia», dignidad, Ética Eudemia, virtud.

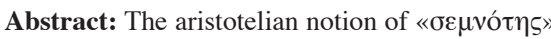
has been generally translated as «dignity», and the two dispositions that flaks this intermediate

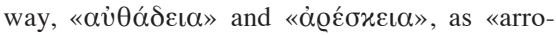
gance» and «servility». In this paper I will argue that the Eudemian Ethics passage about the

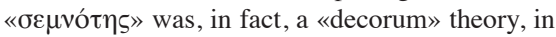
which defiency is «rudeness» and excess «obsequiousness». Aristotle's decorum was not the same as Cicero's decorum, but it was the same as the expression «guardar el decoro», which crystallised in the Spanish Golden Age.
\end{abstract}

Keywords: «aréskeia», «authádeia», dignity, Eudemian Ethics, virtue.

Tanto en la Ética Eudemia como en la Retórica, Aristóteles nos habla de un «modo de

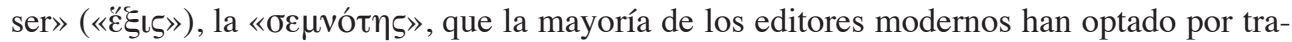
ducir como «dignidad», pero cuyo verdadero sentido, si nos atenemos a lo que manifiesta el propio Aristóteles, se ajusta mucho mejor a nuestro concepto de «decoro», tal y como

Recibido: 02/08/2017. Aceptado: 12/08/2018.

* Investigador Predoctoral en Formación (FPI). Departamento de Filosofía. Universidad Nacional de Educación a Distancia (UNED). dhernandez@fsof.uned.es. Sus principales líneas de investigación son: historia de la filosofía antigua, filosofía política y teoría de la democracia. Dos publicaciones recientes: «El cuidado de nosotros mismos. El descuido de la democracia en Michel Foucault», en Teresa Oñate Zubía et al. (eds.), Hermenéuticas del cuidado de sí: Cuerpo. Alma. Mente. Mundo, vol. 1, Madrid, Editorial Dykinson, 2017, pp. 341-355; y «La dignidad de la palabra del pueblo: la parresía democrática frente a Michel Foucault», en Revista Logos. Anales del Seminario de Metafísica, Universidad Complutense de Madrid (UCM), vol. 51 (2018), pp. 115-137. 
intentaré demostrar en este artículo. El principal problema es que Aristóteles no ofrece una definición positiva de la semnótes, sino que la describe como un estado intermedio

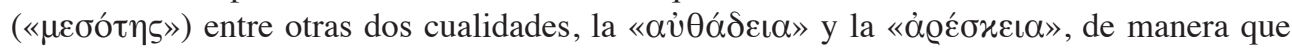
nuestra interpretación de la primera dependerá de la interpretación que hagamos de las segundas. Por suerte, la propia teoría del término medio nos ofrece algunas indicaciones para saber si andamos por el buen camino. Así, como norma general, las dos cualidades que flanquean al término medio se presentan como un «exceso» y un «defecto», de manera que

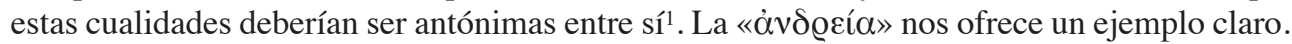

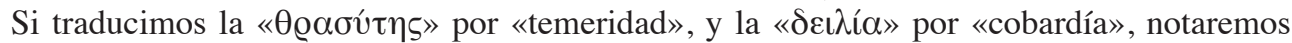
que guardan entre sí, como quería Aristóteles, la misma relación de oposición que cada una

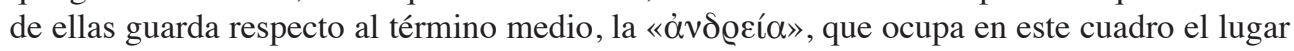
de la «valentía» ${ }^{2}$.

En el caso que nos ocupa, la semnótes, los traductores se han encontrado con un verdadero problema a la hora de conseguir el efecto que buscaba Aristóteles. Megino Rodríguez lo confiesa con total honestidad cuando reconoce que el significado común de la authádeia, «arrogancia», «no parece el término más adecuado como antónimo de "servilismo, deseo de complacer" (aréskeia)» ${ }^{3}$. El objetivo principal de mi artículo es resolver este problema, pero en la conclusión mostraré que no se trata de una mera cuestión filológica, sino de un aspecto importante relacionado con el tratamiento aristotélico de la noción de dignidad.

\section{La semnótes}

Los escritos de Aristóteles apenas dedican unas líneas a la semnótes, razón por la que no ha recibido mucha atención por parte de la crítica ${ }^{4}$. En la Ética Eudemia aparece encuadrada dentro de una serie de estados intermedios que, si bien resultan elogiables, no constituyen

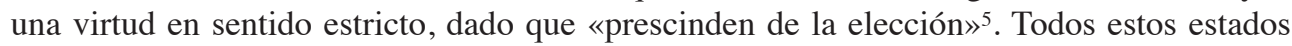
forman parte de la división de los afectos, y por ser naturales, contribuyen a las virtudes «naturales», pues cada virtud, «de alguna manera existe por naturaleza y también, de otra manera, acompañada de sensatez», como el «respeto» («aỉó́s») contribuye a la «modera-

1 Cf. Arist., EN, 1108b 10-20.

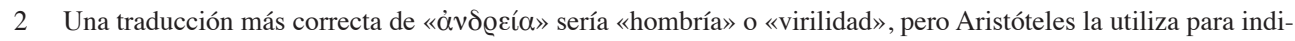
car lo que la naturaleza de la hombría tiene de valentía.

3 Cf. Aristóteles (2002), Ética Eudemia, introducción, traducción y notas de Carlos Megino Rodríguez, Madrid: Alianza Editorial, pp. 70-71, nota 16.

4 Normalmente, se ha tratado de ella dentro del debate en torno a las llamadas «Questionable Mean-Dispositions». Cf. el contenido y las referencias de este debate en Fortenbaugh, W. W. (1968), «Aristotle and the Questionable Mean-Dispositions», Transactions and Proceedings of the American Philological Association, Vol. 99, pp. 203321; y Gottlieb, P. (2009), The Virtue of Aristotle's Ethics, Cambridge: Cambridge University Press, pp. 46-48. Algunas de estas disposiciones (no la semnótes) son mencionadas también en la EN, donde son tratadas como virtudes morales relacionadas con la comunicación por medio de palabras y acciones (cf., entre otros, $E N 1108$ a 11). Para estas diferencias entre la EE y la EN, cf. Kenny, A. (2016), The Aristotelian Ethics: A Study of the Relationship Between the Eudemian and Nicomachean Ethics of Aristotle, $2^{\mathrm{a}}$ Ed., Oxford: Oxford University Press. Para la semnótes, cf. p. 233.

5 Arist., EE, 1234a 25. 


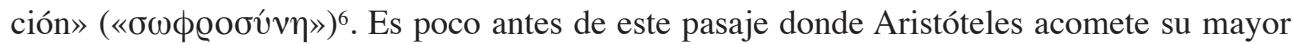
esfuerzo por definir el campo de la semnótes:

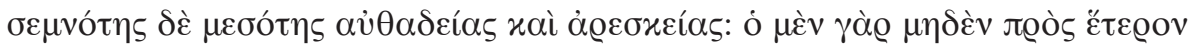

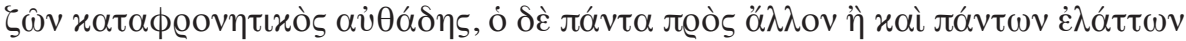

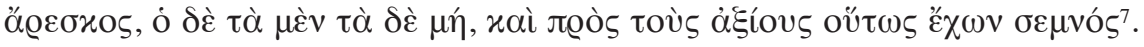

Veamos la traducción de Pallí Bonet ${ }^{8}$ para la edición de Gredos:

La dignidad es un término medio entre la antipatía y la obsequiosidad. Aquel que vive despreciando a todos es antipático; el que en todo hace caso a los demás y es inferior a todo, es obsequioso; pero aquel que actúa de esa manera en unos casos pero en otros no, y respecto a las personas que lo merecen, es digno.

Como podemos comprobar, el pasaje no nos brinda ninguna definición positiva de la semnótes, por lo que la apuesta por la palabra «dignidad» tiene que tomar pie en su significado en otros contextos o ser deducida a partir de la explicación que Aristóteles ofrece de los estados que la flanquean por los extremos. Estos estados, como hemos adelantado, son la authádeia y la aréskeia, que Pallí Bonet traduce por «antipatía» y «obsequiosidad». Las menciones que encontramos en la Retórica son todavía más escuetas. En general, la mayoría de los traductores modernos han optado por traducir la semnótes por «dignidad», pero han oscilado bastante en lo que concierne a la authádeia y la aréskeia. La relación que presento de estas traducciones en la tabla 1 no es exhaustiva, pero es bastante representativa de lo que nos podemos encontrar en las diferentes lenguas.

Tabla 1

\begin{tabular}{|c|c|c|c|}
\hline \multicolumn{4}{|c|}{ Ética Eudemia } \\
\hline & 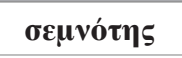 & 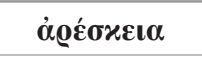 & $\alpha \dot{v} \theta \dot{\alpha} \delta \varepsilon \iota \alpha$ \\
\hline Página Bekker & $1233 b$ 34-38 & $1233 b 34-38$ & $1233 b$ 34-38 \\
\hline Dalimier (2013) & dignité & complaisance & arrogance \\
\hline Simpson (2013) & dignity & fawning & disagreeableness \\
\hline Kenny (2011) & dignity & servility & churlishness \\
\hline Medina González (2007) & dignidad & servilismo & arrogancia \\
\hline Megino Rodríguez (2002) & dignidad & servilismo & arrogancia \\
\hline Gómez Robledo (1994) & dignidad & obsequiosidad & arrogancia \\
\hline Pallí Bonet (1985) & dignidad & obsequiosidad & antipatía \\
\hline
\end{tabular}

6 Ibídem, 1234a 25-35.

7 Ibídem, 1233b 34-38.

8 Aristóteles (1985), Ética Nicomaquea. Ética Eudemia, introducción por Emilio Lledó Iñigo, traducción y notas por Julio Pallí Bonet, Madrid: Gredos. 
Ética Eudemia

\begin{tabular}{|c|c|c|c|}
\hline Dirlmeier (1984) & Würde & Unterwürfigkeit & Selbstgefälligkeit \\
\hline Woods (1982) & dignity & servility & unaccommodatingness \\
\hline Décarie (1978) & dignité & complaisance & égoïsme \\
\hline Rackham (1935) & dignity & Obsequiousness $^{9}$ & Self-will ${ }^{10}$ \\
\hline Ross (1915) & dignity & servility & stubbornness \\
\hline $\begin{array}{l}\text { Barthélemy-Saint Hilaire } \\
\text { (1856) }\end{array}$ & dignité & complaisance & égoïsme \\
\hline Fritzsche (1851) & gravitas & assentatio & insolentia \\
\hline \multicolumn{4}{|c|}{ Retórica } \\
\hline & 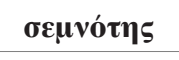 & 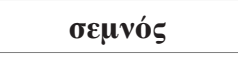 & $\alpha \dot{v \theta \alpha} \boldsymbol{\alpha} \boldsymbol{~}$ \\
\hline Libro, capítulo, sección & 2.17 .4 & $1.9 .29 / 2.17 .4$ & 1.9 .29 \\
\hline Rapp (2002) & Würde & ehrwürdig & selbstgefällig \\
\hline Ramírez Trejo (2002) & dignidad & majestuoso & arrogante \\
\hline Bernabé (1998) & importancia & importante $^{11}$ & altanero \\
\hline Plebe (1992) & dignità & superiore & temerario \\
\hline Kennedy (1991) & dignity & imposing & arrogant \\
\hline Racionero (1990) & gravedad & digno & arrogante \\
\hline Tovar (1953) & dignidad & digno & arrogante \\
\hline Buhle (1793) & gravitas & gravis & arrogans \\
\hline
\end{tabular}

El diccionario Liddell-Scott también recogió para la semnótes el mismo significado: «solemnity, dignity», o referido a personas, «seriousness, dignity» ${ }^{12} \cdot$ ¿Pero en qué sentido hablamos de «dignidad» cuando traducimos la semnótes aristotélica? Si nos atenemos al uso del español ${ }^{13}$, creo que podemos reducir la intención de los traductores al campo semántico

9 En $E E$ 1221a 1-30 «Subservience».

10 En $E E$ 1221a 1-30 «Stubbornness».

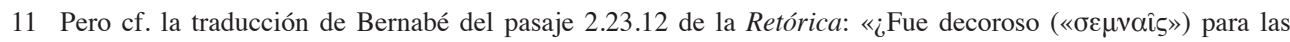
augustas diosas someterse al consejo del Areópago y no va a serlo para Mixidémides?».

12 Liddell, H. G. and Scott, R. (1940), A Greek-English Lexicon, revised and augmented throughout by Sir Henry Stuart Jones, with the assistance of Roderick McKenzie, $9^{\text {a }}$ Edición, Oxford: Clarendon Press. A partir de un pasaje de Eurípides, el diccionario recoge todavía una tercera acepción, que aparece cuando la palabra se

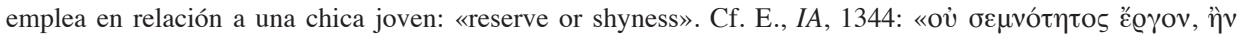
óvó $\mu \varepsilon \theta \alpha »$, es decir, «no hay lugar para la reserva (o la timidez), cuando estamos angustiadas». Carlos García Gual, en su versión de este fragmento, propone traducir la palabra semnótes por «cortesía», lo que se acerca bastante a la noción de decoro que propongo en este artículo.

13 Para todas las definiciones que utilizaré en adelante de los términos españoles, cf. Real Academia Española (2014), Diccionario de la lengua española, $23^{\mathrm{a}}$ ed., Madrid: Espasa. Los ejemplos están sacados de las entradas correspondientes de VV.AA. (1997), Clave: Diccionario de uso del español actual, prólogo de Gabriel García Márquez, Madrid: Ediciones SM. No puedo entrar aquí en la discusión sobre el origen y el significado del 
de tres acepciones: «cualidad de digno»; «excelencia, realce»; y «gravedad y decoro de las personas en la manera de comportarse ${ }^{14}$. Empezando por la cualidad, la dignidad se utiliza en varios sentidos. En primer lugar, para expresar que alguien es «merecedor de algo», tanto en sentido favorable como adverso. Así, sería correcto afirmar de una persona que «no es digna de desprecio sino de alabanza», pero también al contrario, es decir, que es digna de desprecio y no de alabanza. En segundo lugar, la cualidad de digno es lo que se corresponde o resulta proporcionado al mérito y condición de alguien o algo, como cuando decimos: «tuvo una digna recompensa por su honradez». Y en último lugar, es lo «que tiene dignidad o se comporta con ella», como el que «lleva una vida digna dedicada a la familia y al trabajo».

La «excelencia» o «realce» es la segunda acepción de «dignidad» que podemos sacar a colación en relación a la semnótes. Hablamos de «excelencia» para indicar la superior calidad o bondad que hace que algo resulte singularmente digno de aprecio y estimación, como cuando decimos: «la excelencia de sus versos le hizo alcanzar gran fama». Utilizamos también esta palabra para señalar el «tratamiento de respeto y cortesía que se da a algunas personas por su dignidad o empleo», verbigracia: «su excelencia el embajador». El «realce», por su lado, encierra el significado de «lustre, estimación, grandeza sobresaliente», como se deja notar en el siguiente ejemplo: «la asistencia de la académica dio realce a la entrega de premios». En suma, aludir a la dignidad, en cuanto excelencia o realce, implica poner el acento en la superioridad, en la grandeza de lo que nos parece digno. Y esto es lo que la distingue netamente de la primera acepción, donde incluso lo más bajo puede ser digno, aunque sea de nuestro desprecio.

Sin embargo, como veremos enseguida, lo que más se acerca a la semnótes aristotélica del campo semántico de la dignidad es la tercera acepción, que alude a la gravedad y el decoro que tienen las personas en la manera de comportarse. En efecto, en el estado que describe Aristóteles se encuentran involucradas las connotaciones que implican la gravedad y el decoro. Pero hay una diferencia importante. Para Aristóteles, estas connotaciones son algo que tenemos en relación a los demás, es decir, somos graves y decorosos porque nos comportamos con la gravedad y el decoro que los demás se merecen, mientras que para la dignidad, se trata de lo que este comportamiento nos hace merecer a nosotros mismos. Cuando decimos de alguien: «actuó con mucha dignidad», no importa ante quién lo hizo, porque la dignidad de su comportamiento está referida a su propia valía. La dignidad de los otros no tiene ninguna relevancia para el comportamiento digno, porque alguien puede actuar con dignidad incluso estando a solas en una isla desierta. Sin embargo, esto no es posible para la semnótes aristotélica. Se trata de un estado afectivo relacional. Y al igual que todos

concepto moderno de dignidad. Para ello, entre otros, cf. Lebech, M. (2009), On the Problem of Human Dignity: A Hermeneutical and Phenomenological Investigation, Würzburg: Königshausen \& Neumann; Debes, R. (2009), «Dignity's Gauntlet», Philosophical Perspectives, Vol. 23, Ethics, pp. 45-78; y Habermas, J. (2010), «El concepto de dignidad humana y la utopía realista de los derechos humanos», Diánoia, volumen LV, número 64: pp. 3-25.

14 Las acepciones completas son: «1. f. Cualidad de digno. I 2. f. Excelencia, realce. I 3. f. Gravedad y decoro de las personas en la manera de comportarse. I 4. f. Cargo o empleo honorífico y de autoridad. I 5. f. En las catedrales y colegiatas, prebenda que corresponde a un oficio honorífico y preeminente, como el deanato, el arcedianato, etc. I 6. f. Persona que posee una dignidad (\| prebenda). U. t. c. m. I 7. f. Prebenda del arzobispo u obispo. Las rentas de la dignidad. I 8. f. En las órdenes militares de caballería, cargo de maestre, trece, comendador mayor, clavero, etc.». 
los bienes relacionales, no podemos experimentarlo sin otras personas ${ }^{15}$. No somos amigos de nosotros mismos, sino de nuestros amigos. Y amamos a nuestros amigos, no por lo que hay en nosotros de amable, sino por lo que encontramos en ellos digno de ser amado. Lo mismo sucede con la semnótes. No podemos tenerla sino en relación a otros, y no por lo que nosotros valemos, sino porque nos comportamos de acuerdo a lo que valen los demás. Es en este sentido en el que el pasaje 1233b 34-38 de la Eudemia afirma que el semnós es el que

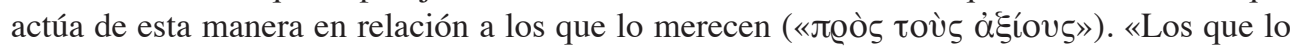
merecen», es decir, los que son dignos de ella. La dignidad, tanto en este pasaje como en el resto de Aristóteles, está mucho más relacionada con el campo semántico de la «ả̧ $\xi i ́ \alpha »$

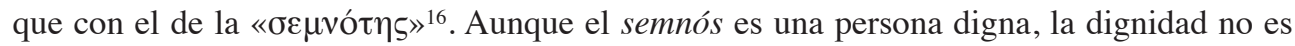
la semnótes.

\section{El decoro}

Entre las acepciones de $«$ decoro ${ }^{17}$, hay tres que guardan una estrecha relación con la semnótes aristotélica: en primer lugar, «honor, respeto, reverencia que se debe a una persona por su nacimiento o dignidad». A continuación: «circunspección, gravedad», lo que vuelve a remitirnos al respeto, o a la seriedad, como algo que uno inspira, o como la manera en la que se comporta uno. Y por último: «honra, pundonor, estimación». Cuando decimos: «La embajadora fue tratada con el debido decoro», estamos haciendo notar dos cosas que conviene tener en cuenta. Por un lado, que la embajadora tiene decoro. Lo que la convierte en una persona merecedora de un tratamiento decoroso es su propio decoro, es decir, su dignidad, y en este sentido, también podríamos haber dicho: «La embajadora fue tratada con la debida dignidad». Aquí, tanto la dignidad como el decoro, están referidos a la propia persona. Pero junto a este elemento, aparece otro nuevo. Y es que en la frase «la embajadora fue tratada con el debido decoro», la persona que tiene el decoro, en el sentido de «dignidad», es la embajadora, y por tanto, no se trata del decoro de la persona que se comporta, sino de aquella ante la que nosotros nos comportamos. Frente a lo que se pone en juego cuando una persona actúa con dignidad, que es su propia valía, tenemos aquí un segundo sentido, que hace referencia a la valía del otro. Así, por un lado (primer sentido de la frase), el otro ante quien nos comportamos tiene decoro, pero por otro (segundo sentido), somos nosotros quienes nos comportamos con decoro cuando tratamos a esta persona con el decoro (la dignidad) que se merece. Este segundo sentido es el que está registrado en la

15 Para los bienes relacionales en Aristóteles, cf. Nussbaum, M. (1995), La fragilidad del bien. Fortuna y ética en la tragedia y la filosofía griega, traducción de Antonio Ballesteros, Madrid: Visor.

16 Para la relación de la «ỏ $\xi^{\prime}(\alpha »$ con la noción de dignidad en Aristóteles, cf. Lebech, M. (2009), op. cit, p. 30 y ss.

17 Decoro: «1. m. Honor, respeto, reverencia que se debe a una persona por su nacimiento o dignidad. I 2 . m. Circunspección, gravedad. I 3. m. Pureza, honestidad, recato. I 4. m. Honra, pundonor, estimación. I 5. m. Nivel mínimo de calidad de vida para que la dignidad de alguien no sufra menoscabo. Su sueldo le permite vivir con decoro. 1 6. m. Arq. Parte de la arquitectura que enseña a dar a los edificios el aspecto y propiedad que les corresponde según sus destinos respectivos. 17. m. Ret. Adecuación del lenguaje de una obra literaria a su género, a su tema y a la condición de los personajes. I 8. m. T. lit. Conformidad entre el comportamiento de los personajes de una obra y sus respectivas condiciones». «Guardar el decoro»: «1. loc. verb. Comportarse con arreglo a la propia condición social». «Guardar el decoro a alguien o a algo»: «1. loc. verb. Corresponder con actos o palabras a su estimación o a su merecimiento». 
acepción «guardar el decoro a alguien o algo», una locución verbal que significa: «corresponder con actos o palabras a su estimación o a su merecimiento». Si en su lugar, dijéramos, simplemente, «guardar el decoro» (suprimiendo a quién), el significado sería completamente distinto: «comportarse con arreglo a la propia condición social» (una vez más, sería la embajadora la que guarda el decoro). Guardar el decoro a alguien (a la embajadora), nunca está relacionado con nuestra propia condición social, sino con la clase de actos y palabras con las que debemos corresponder a los méritos de otras personas. $\mathrm{Y}$ es precisamente esta clase de decoro la que refleja el valor relacional de la semnótes aristotélica. El semnós tiene dignidad, pero lo que lo caracteriza en cuanto semnós es que sabe cómo guardar el decoro a otras personas.

Conviene aclarar que este sentido de la palabra «decoro» no se encuentra en el decorum de la retórica clásica o de la obra de Cicerón, sino que se trata de un neologismo semántico que tomará forma durante el Siglo de Oro español. El decorum ciceroniano toma como punto de partida lo que «los griegos» llamaban «л@érov», es decir, «lo conveniente»18, y está referido a dos aspectos: el primero, la habilidad del orador para determinar cuál es el estilo apropiado para la declamación de un discurso en situaciones particulares; y el segundo, una de las cuatro virtudes cardinales, la que se ocupa del «orden y medida en cuanto se hace y se dice», a partir de un principio de nuestra naturaleza racional que es capaz de percibir «el orden, lo conveniente y la medida en los hechos y en las palabras» ${ }^{19}$. En este último sentido, el decoro implica «el comedimiento, y cierto ornato de la vida, la templanza y la moderación, así como la calma de todas las perturbaciones del ánimo y la justa medida en todas las cosas» ${ }^{20}$. Tenemos, por consiguiente, que tanto el decorum retórico como el decorum ético, en Cicerón, están referidos a la condición de la persona que tiene el decoro. Será en el Siglo de Oro español cuando el decoro adopte por primera vez la connotación que lo emparentará con la semnótes aristotélica. Entonces, la palabra «decoro» adquirió un triple sentido. Juan de Valdés nos habla de los dos primeros: por un lado, utilizamos decoro «cuando queremos decir que uno se gobierna en su manera de vivir conforme al estado y condición que tiene», y por otro, cuando «los representadores de comedias», «guardaban lo que convenía a las personas que representaban», que es el concepto horaciano de conformidad con la naturaleza y verosimilitud de los caracteres ${ }^{21}$. Pero Covarrubias nos habla de un tercer sentido: «Decoro vale el respeto y mesura que se debe tener delante de los mayores y personas graves» ${ }^{22}$. Y es precisamente esta connotación, que alude al respeto, deferencia o miramientos que conviene demostrar ante determinadas personas, la que nos devuelve a la semnótes aristotélica. Así, Cervantes escribirá: «[la] puntualidad de don Quijote en guardar el decoro a la caballería», «el decoro que siempre le había guardado [a Dulcinea]»

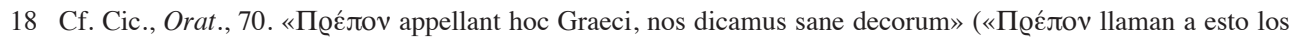
griegos, llamémoslo muy bien nosotros decoro»).

19 Cic., Off., I, 14-15. Cf. Kapust, D. (2012), «Cicerón: El decorum y la moralidad de la retórica», Praxis Filosófica Nueva Serie, No 35 , pp. 257-282.

20 Cic., Off., I, 93. Cf. Kaust, D. (2012), op. cit., p. 272.

21 Valdés, J. (1736/1969), Diálogo de la lengua, Madrid: Clásicos Castalia, p. 141. Citado en Chevalier, M. (1993), «Decoro y decoros», Revista de Filología Española, tomo LXXIII, no 1/2, p. 5.

22 Covarrubias, S. (1611/1979), Tesoro de la lengua castellana, Madrid: Turner, p. 645b. Citado en Chevalier, M. (1993), op. cit., p. 5. 
y «enemigo del decoro que se debe a las reales personas» ${ }^{23}$. Esta tendencia se confirmará a lo largo del Siglo de Oro, con el empleo creciente de las fórmulas «guardar el decoro», «perder el decoro» y «decoro y respeto». Toda esta evolución ha sido estudiada con detalle en un excelente trabajo de Chevalier, que concluye que la forma de respeto que terminará manifestándose ordinariamente en los personajes novelescos y dramáticos, «empléese o no la palabra decoro, será el respeto debido a los demás: amadas, amigos y señores ${ }^{24}$. Y añade:

El respeto se va a expresar en las formas de hablar, en las formas de hablar a otra persona. Otra persona que dentro de este proceso evolutivo viene a ocupar el sitio céntrico. Se sigue empleando la palabra decoro mientras ha variado el objeto a que se aplica. Dentro de los conceptos horacianos era fundamental el carácter de la persona que hablaba (...); dentro de la comedia lopesca o la novela cervantina resulta fundamental la persona a la que se dirige el hablante. Un hablante que amolda su hablar sobre la calidad del interlocutor ${ }^{25}$.

\section{La authádeia y la aréskeia}

Veremos con más claridad cómo esta evolución del decoro lo aproxima a la semnótes aristotélica si volvemos al pasaje de la Ética Eudemia que hemos tratado al principio de este artículo. Como tuvimos ocasión de comprobar, Aristóteles no ofrece ninguna definición positiva de la semnótes, pero podemos intentar obtenerla a partir de los estados afectivos que la condicionan por defecto y por exceso: la authádeia y la aréskeia.

Como en el caso de la semnótes, la traducción en este contexto de «authádeia» por «arrogancia» presenta varios problemas. Aunque la arrogancia implica una actitud hacia el otro, lo que la caracteriza es más bien la actitud hacia uno mismo. Arrogante significa «altanero, soberbio» ${ }^{26}$. Tanto la altanería como la soberbia remiten en última instancia a la vanidad $^{27}$. Decimos de una persona que es arrogante cuando adolece de un exceso de orgullo o se comporta de forma soberbia. Es el envanecimiento por la contemplación de las propias prendas lo que la convierte en la clase de persona que menosprecia a las demás. El sentido del authádes es diferente. No se trata tanto de cómo nos vemos a nosotros mismos sino de cómo vemos (y cómo tratamos) a los demás. Lo que dice Aristóteles en la Eudemia es que

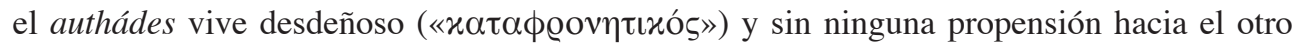

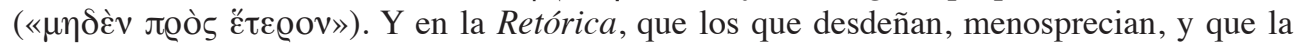
causa del menosprecio es la consideración de que lo menospreciado no tiene ningún valor ${ }^{28}$. Frente a la arrogancia, la authádeia pone el acento en el otro.

23 Cervantes, M. (1605-1615/1998), Don Quijote de la Mancha, presentación y prólogo de Francisco Rico, Barcelona: Galaxia Gutenberg-Círculo de Lectores, I, 27; II, 3; y I, 46.

24 Chevalier, M. (1993), op. cit., p. 8.

25 Ibídem.

26 También «valiente» y «gallardo», pero estos sentidos no tienen que ver con la authádeia.

27 Altivez: «1. f. Orgullo, soberbia»; orgullo: «1. m. Arrogancia, vanidad, exceso de estimación propia, que a veces es disimulable por nacer de causas nobles y virtuosas»; soberbia: «1. f. Altivez y apetito desordenado de ser preferido a otros. I 2. f. Satisfacción y envanecimiento por la contemplación de las propias prendas con menosprecio de los demás».

28 Arist., Rh., 2.2.4. 
En el libro segundo de la Eudemia, Aristóteles había presentado a la aréskeia como «un exceso por complacer», y a la authádeia como un defecto («[complacer] poco y a duras penas» ${ }^{29}$. Pero cuando en el libro tercero relaciona estas cualidades con la semnótes añadirá una precisión importante: la semnótes es un estado intermedio no porque podamos localizarla a medio camino entre la aréskeia y la authádeia, sino porque se manifiesta de una manera o de otra según lo que merezca cada persona. Si traducimos entonces la aréskeia, como ocurre en muchas versiones, por «servilismo» ${ }^{30}$, nos encontraremos con que lo que caracteriza al semnós es ser arrogante con unos y servil con otros. Y esto no resulta fácil de encajar con nuestro concepto de «dignidad», porque la arrogancia y el servilismo, para nosotros, son defectos que difícilmente podemos atribuir a una persona digna ${ }^{31}$.

Pero Aristóteles, como acabamos de ver, no estaba hablando de la dignidad, sino del decoro, y aunque la authádeia estaba tan relacionada con el desdén como la arrogancia, se trataba de dos cosas distintas. «Perder el decoro» significa, en realidad, comportarse con grosería. Y creo que este es el sentido que Aristóteles atribuye a la authádeia cuando la trata como un defecto. Una «grosería» 32 es una descortesía, una falta grande de atención y respeto. Es la cualidad de los que carecen de educación o delicadeza, de los que tratan a la gente con descortesía, o de los que no dan muestras de atención, respeto o afecto hacia otras personas $^{33}$. Teofrasto dedicará a la authádeia un capítulo completo de su obra Caracteres, y la describirá como «una tosquedad en el trato que se manifiesta verbalmente» ${ }^{34}$. Aquí, la relación de ejemplos que nos brinda el discípulo de Aristóteles es tan ilustrativa que los editores de Gredos se convencieron de que la palabra que mejor recoge su significado es «grosería» ${ }^{35}$. Veamos unos cuantos. El authádes, cuando alguien le pregunta: «¿Dónde está Fulano», replica: «Y a mí que me importa». Cuando se le saluda, no contesta. Es incapaz de disculpar a quien le pisa involuntariamente. Maldice a las piedras con las que tropieza. Y no espera a nadie mucho tiempo ${ }^{36}$. Todos estos ejemplos, y algunos más, son manifestaciones de grosería. Un arrogante puede ser grosero. Pero no todos los groseros son arrogantes.

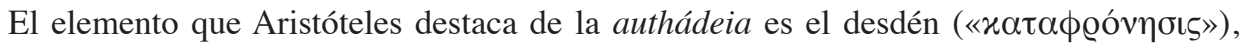
pero aunque la authádeia pudiera sonar igual de mal que nuestra grosería, había una circunstancia en la que este desdén podía resultar aceptable para las personas como Aristóteles: cuando se trataba de la gente importante. Teofrasto, de acuerdo con Aristóteles, critica el reparto indiscriminado de la authádeia, pero Aristóteles matiza en la Eudemia que cuando

29 Arist., EE, 1221a 27-28.

30 Servilismo: «1. m. Condición de servil. | 2. m. Actitud ideológica de los servilones»; servil: «2. adj. Que de modo rastrero se somete totalmente a la autoridad de alguien».

31 Opinión que comparte Sulmasy en su comentario a la definición de la semnótes aristotélica: «This hardly seems the way we use the Word dignity today». Cf. Sulmasy, D. (2007), «Human Dignity and Human Worth», en: Malpas and Lickiss (eds.): Perspectives on Human Dignity. A Conversation, Dordrecht: Springer, p. 11.

32 Grosería: «1.f. Descortesía, falta grande de atención y respeto. I 2. f. Tosquedad, falta de finura y primor en el trabajo de manos. I 3. f. Rusticidad, ignorancia».

33 Grosero: «1. adj. Dicho de una persona: Carente de educación o de delicadeza»; descortesía: «1. f. Falta de cortesía»; cortesía: «1. f. Demostración o acto con que se manifiesta la atención, respeto o afecto que tiene alguien a otra persona».

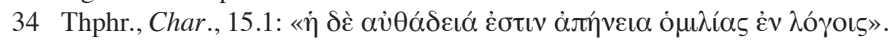

35 También el DGE recoge esta acepción para la obra de Teofrasto.

36 Thphr., Char., 15. 
este reparto no está dirigido por igual a todo el mundo, sino solo a algunas personas (aquellas que se merecen nuestro desdén), entonces la authádeia se convierte en semnótes, la grosería, en decoro. En este pasaje, Aristóteles no da más pistas sobre el tipo de personas en las que está pensando. Pero el libro primero de la Retórica puede ayudarnos a averiguarlo. Aquí, Aristóteles nos habla de una estrategia retórica que consiste en utilizar el parecido que a veces se da entre algunas cualidades que realmente tenemos por otras cualidades que no tenemos, como por ejemplo, cuando presentamos al cándido como si fuera un hombre de bien, o al insensible como a una persona tranquila ${ }^{37}$. Se trata de vestir los defectos con el ropaje de la virtud, o como dice el propio Aristóteles, «de (aprovecharse) en cada caso de estas semejanzas siempre en el sentido de lo mejor» ${ }^{38}$. Pues bien, entre los ejemplos que Aristóteles utiliza para ilustrar este procedimiento nos encontramos con el authádes: «(hay que presentar) al authádes como magnificente y semnós» ${ }^{39}$. Son las mismas dos cualidades que hemos visto aparecer juntas en la Ética Eudemia, con el añadido de que se hallan

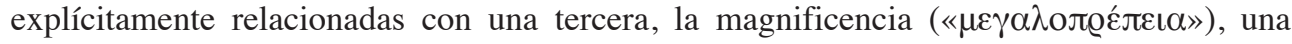
cualidad estrechamente vinculada a la ostentación de los ricos ${ }^{40}$. Que Aristóteles considere en la Retórica que la authádeia pueda pasar por esta clase de semnótes, quiere decir que además de la authádeia vulgar y corriente hay otro tipo de authádeia que podemos asociar específicamente a la gente importante, y que este tipo de authádeia (al menos, para la gente como Aristóteles), era mucho más aceptable que la primera. En esto hemos avanzando algo desde los tiempos de Aristóteles, pero no lo suficiente. Sigue habiendo una doble vara de medir para la grosería. No es lo mismo que una persona corriente no le devuelva el saludo a una persona importante, que una persona importante no le devuelva el saludo a una persona corriente. Aunque estas actitudes resultan cada vez menos disculpables, las personas importantes tienen muchas más opciones de librarse de la acusación de grosería que las personas corrientes. Para la sociedad, o buena parte de ella, están demasiado ocupadas como para estrechar todas las manos, responder a todas las preguntas, o esperar a nadie mucho tiempo. $\mathrm{Y}$ es precisamente a esta clase de personas a las que se refiere Aristóteles en la Eudemia. La authádeia, cuando se trata de la actitud desdeñosa que las personas importantes tienen en relación a las personas de poca valía, se convierte en una forma de guardar el decoro ${ }^{41}$.

Aristóteles vuelve a hacerse eco de esta relación de proximidad entre la authádeia, la megaloprépeia y la semnótes en otro pasaje de la Ética Eudemia ${ }^{42}$. Pero aquí ampliará el arco de la relación para introducir a la « $\mu \varepsilon \gamma \alpha \lambda \sigma \psi v \chi i ́ \alpha »$ (la «magnanimidad»), la virtud que mejor se deja relacionar con la dignidad en Aristóteles. Después de mencionar el parecido

37 Arist., Rh., 1.9.28-29.

38 Aristóteles no inventó este procedimiento clásico de la retórica epidíctica, pero sí fue el primero en razonarlo. Cf. el comentario de Quintín Racionero en Aristóteles (1990), Retórica, introducción, traducción y notas por Quintín Racionero, Madrid: Editorial Gredos, p. 247, nota 233.

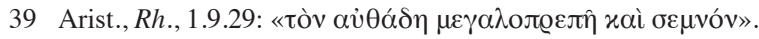

40 Arist., EN, 1122a 18-20: «Parece que debemos hablar, a continuación, de la magnificencia, puesto que también ésta se considera una virtud relacionada con las riquezas».

41 Que el decoro podía pasar por grosería, y no solo la grosería por decoro (y que, por tanto, no todo el mundo pensaba lo mismo que Aristóteles), podemos comprobarlo en el Erótico de Demóstenes, donde advierte que

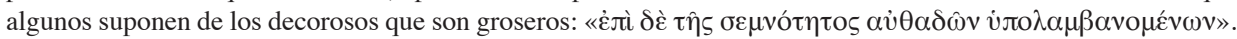
Cf. D., 61.14 .

42 Arist., EE, 1232a 23-34. 
entre el authádes y el semnós, añadirá que el megalópsichos puede parecerse también tanto al semnós como al megaloprepés, «ya que [la magnanimidad] acompaña, evidentemente, a todas las virtudes». Pero no se trata solo de esto. La magnanimidad y el decoro tienen un

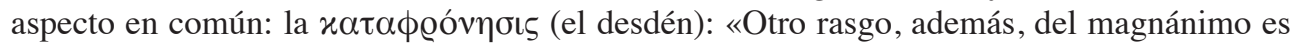
que parece ser desdeñoso» ${ }^{43}$. Se cierra, por tanto, el círculo entre la authádeia, la semnótes, y la kataphrónesis. Lo que tiene en común el grosero con el decoroso es el desdén, pero la diferencia es que el decoroso solo desdeña a las personas que lo merecen, tal y como actúan las personas magnánimas. El magnánimo se preocupa de pocas cosas, y cuando lo hace, es porque estas cosas son importantes, y no porque simplemente lo parezcan. Se interesa más por la opinión de un hombre honesto que por la de cualquier otro. Su vida está marcada por la despreocupación («ỏ $\lambda \hat{i} \gamma \omega \varrho o \varsigma »)$. Busca ante todo el honor, y vive desdeñoso de la multitud $^{44}$. En la Ética Nicomaquea añadirá: el magnánimo es altivo con los de elevada posición y mesurado con los de clase media, porque lo difícil y decoroso es comportarse con superioridad respecto a los primeros. Hacerlo con los humildes sería demasiado vulgar y fácil, como utilizar la fuerza física contra los débiles ${ }^{45}$. No cabe duda de que la magnanimidad es la virtud a la que acompaña el decoro ${ }^{46}$. Pero aunque guardar el decoro hace más digno al hombre magnánimo, el decoro no es la dignidad.

Si vamos ahora con la aréskeia, nos encontraremos ante una situación parecida a la que acabamos de dejar con la authádeia. La mayoría de los traductores han optado por verterla como «servilismo» («servility»), frente a la decisión de Rackham y el diccionario LiddellScott, que adoptaron «obsequiousness». Pallí Bonet, Gomez Robledo y el DGE han seguido esta última opción ${ }^{47}$. En general, la aréskeia podía tener el mismo sustrato peyorativo que

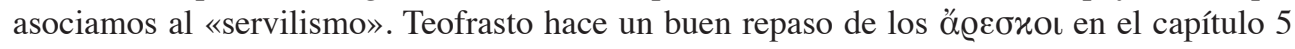
de sus Caracteres $^{48}$, y Aristóteles los describe en el libro cuarto de la Nicomaquea como aquellas personas que con tal de complacer no se oponen a nada y son capaces de alabar cualquier $\cos ^{49}$. Pero la elección de «obsequiosidad» nos brinda dos ventajas importantes frente a «servilismo». En primer lugar, que la aréskeia, al contrario que el servilismo, podía tener también una connotación positiva (el gusto o deseo por complacer), y solo con la «obsequiosidad» podemos hacernos eco de este doble sentido. Una persona obsequiosa es la que se comporta con cortesía y está atenta a la voluntad de otras, pero si este comportamiento es o no servil dependerá de lo que las otras personas merezcan. Nadie llamaría servil, por ejemplo, a las atenciones que muestra el anfitrión por los invitados a su casa. Cuando las

43 Arist. $E E, 1232$ a $39-40$.

44 Arist., $E E, 1232$ a 40-1232b 20.

45 Arist., EN, 1124b 17-25. Simpson utiliza este pasaje para sostener que el motivo de que la semnótes no aparezca en la $E N$ es porque Aristóteles la incluye dentro de la magnanimidad. Cf. Aristotle (2013), The Eudemian Ethics of Aristotle, Translated with Explanatory Comments by Peter L. P. Simpson, New Brunswick and London: Transaction Publishers, p. 302.

46 El hombre corriente también puede alcanzar una especie de magnanimidad, siempre y cuando no se considere a sí mismo acreedor de más dignidad de la que merece. Cf. EE 1233a 16-30. Para las disposiciones intermedias que acompañan a determinadas virtudes (como el respeto a la moderación), cf. EE, 1234a 24-35 (aunque no se explicita a qué virtud corresponde la semnótes).

47 En el caso del DGE, junto a «adulación» y «servilismo».

48 Thphr., Char., 5.

49 Arist., EN, 1126b 11-15. 
personas a las que se la ofrecemos son dignas de nuestro respeto, la obsequiosidad, lejos de ser un síntoma de servilismo, es un testimonio de nuestra atención y decoro. Y esto nos lleva al segundo argumento a favor de ella. La obsequiosidad incluye un elemento de urbanidad del que carece el servilismo. Y creo que este elemento formaba parte del efecto que Aristóteles buscaba conseguir con el contraste entre la authádeia y la aréskeia, la grosería y la obsequiosidad. Estas cualidades se oponen entre sí, al igual que cada una de ellas es opuesta al decoro ${ }^{50}$.

La descripción que hace Teofrasto de la authádeia y la aréskeia en sus Caracteres no es muy halagüieña. Pero Aristóteles recortó de cada uno de estos modos de ser una cualidad que podía incorporar a su noción de semnótes. De la authádeia, extrajo el desdén, y de la aréskeia, el deseo por complacer. No hay nada elogiable en desdeñar o intentar complacer a todo el mundo, pero sí en la disposición a hacerlo con las personas adecuadas. Aristóteles llamó semnótes a esta disposición, y lo hizo porque la palabra semnótes le permitía incorporar con facilidad estas dos connotaciones que había recortado de la authádeia y la aréskeia. ¿Cómo sonaba la semnótes en los oídos de un griego del siglo IV a.C.?

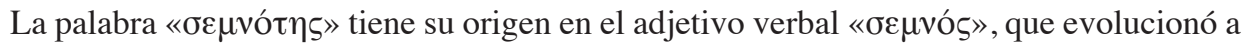

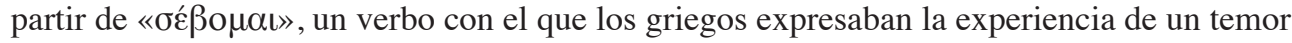
respetuoso, especialmente, cuando se trataba de los dioses, como testimonian los sustantivos

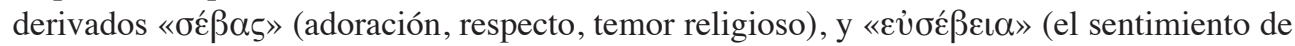

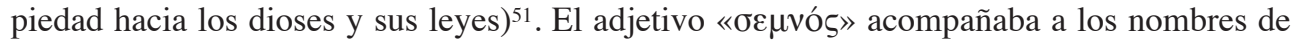
algunos dioses, en particular, Deméter y las Erinias, y a personas que eran importantes y

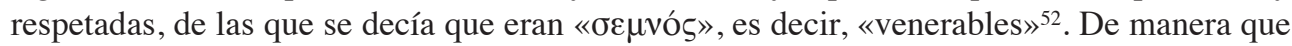

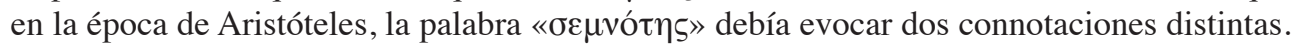
Por un lado, la venerable respetabilidad del $\sigma \varepsilon \mu v o ́ s$, y por otro, el sentimiento de adora-

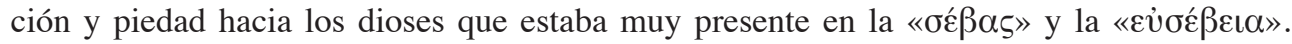
La reminiscencia de la piedad era lo que permitía entroncar a la semnótes con la aréskeia. El decoroso se esfuerza por complacer a los que son dignos de sus atenciones, al igual que el piadoso se esfuerza por complacer a los dioses. Y el desapego a la banalidad era lo que hacía que el desdén de la authádeia pudiera resonar en la manera de ser de los decorosos.

Probablemente, las dificultades para acceder al sentido de la semnótes sean una consecuencia de que en el paso de la semnótes a la «gravitas» se perdió el sentido de la piedad que evocaba el semnós. La gravitas denotaba importancia, solemnidad, gravedad, pero rompió el vínculo que la semnótes tenía con la práctica de la piedad a los dioses. Se abrió el camino de la dignidad, pero se interrumpió la cadena de sentido que hacía que la semnótes tuviera relación con los otros.

50 Para la oposición de la authádeia y la semnótes, cf. Arist., EE, 1232a 23-25: «Por eso, los caracteres contrarios reivindican, a veces, la correspondiente cualidad; por ejemplo (...), el grosero la del decoroso (...), pues se interesan por las mismas cosas y, hasta un cierto punto, son limítrofes» (trad. Pallí Bonet, 1985). Aquello en relación a lo que reivindican la misma cualidad, queda claro con la lectura del pasaje 1233b 34-38: «

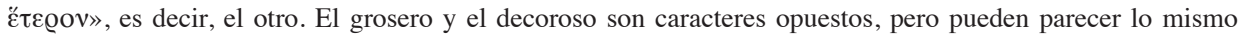
porque ambos manifiestan una escasa propensión hacia el otro: el grosero, hacia todo el mundo, el decoroso, solo hacia quien merece su desdén. El mismo argumento vale para la aréskeia.

51 Chantraine, P. (1968-1980), Dictionnaire etymologique de la langue grecque: histoire des mots, Paris: Éditions Klincksieck, p. 992.

52 Ibídem, p. 993. 


\section{Conclusión}

Las dificultades para interpretar el pasaje de la Ética Eudemia sobre la semnótes se deben más a un problema de traducción que al texto del propio Aristóteles. La versión de los términos que propongo no es completamente nueva. La «aréskeia» fue traducida por «obsequiosidad» en las versiones de Rackham, Pallí Bonet y Gómez Robledo, y Kenny tradujo «authádeia» por «churlishness», que equivale a nuestra «grosería». El problema es que el efecto de la antinomia entre la aréskeia y la authádeia solo aparece cuando elegimos estas dos soluciones al mismo tiempo (lo contrario de la obsequiosidad, por ejemplo, es la grosería, y no la antipatía). Pero la mayor dificultad proviene de la traducción de la propia semnótes. No se trataba de la dignidad, sino de la disposición a comportarse de acuerdo a la dignidad de los otros. En este sentido, la traducción más apropiada es «decoro», pero entendiendo que el decoroso es el que guarda el decoro a los demás.

En virtud de estos argumentos, mi propuesta de traducción del fragmento 1233b 34-38 es la siguiente:

El decoro es un estado intermedio entre la grosería y la obsequiosidad. Aquel que vive desdeñoso, sin ninguna inclinación hacia otro, es grosero; el que en todo hace caso a los demás y es inferior a todos es obsequioso, y el que guarda esta manera de ser en unos casos pero no en otros, y respecto a los que lo merecen, es decoroso.

El hallazgo de lo que podríamos describir como una ética del decoro en Aristóteles tiene varias implicaciones importantes. Por un lado, que la virtud, para el estagirita, no se presenta desnuda, sino que lo hace revestida de una manera particular de manifestarse. Para ser magnánimo no basta solo con dejarse preocupar únicamente por las cosas importantes. Hay que saber cuál es la manera adecuada de mostrar esta preocupación a los demás. En ocasiones, el magnánimo deberá exhibir su interés. En otras, su desdén. Pero será el decoro lo que le disponga de una manera o de otra, según requiera la situación o la persona. El decoro, por decirlo gráficamente, es la etiqueta de la virtud, y muy especialmente, de una de las virtudes más caras para Aristóteles: la magnanimidad. Y esto nos conduce a la segunda implicación importante. Puesto que la magnanimidad se ocupa sobre todo de la cuestión de la timés3, y la timé, tal y como recoge el diccionario Liddell-Scott, es una noción que se encuentra a caballo entre nuestras acepciones del honor y la dignidad, toda esta problemática en torno a la interpretación de la semnótes se traslada forzosamente al corazón de la teoría de la virtud. Si la semnótes fuera la dignidad, entonces nos encontraríamos con que Aristóteles trata de la dignidad como si perteneciera a dos disposiciones distintas. Pero lo que hace en realidad es hablarnos de una sola virtud, la magnanimidad, y de una disposición que contribuye a ella, el decoro. Este repliegue de la dignidad (en sentido fuerte) del campo semántico de la semnótes nos despeja el camino hacia lo más relevante, y es que en Aristóteles hay efectivamente una ética de la dignidad (de la que la ética del decoro es subsidiaria), que se encuentra repartida entre la timé y la axía, y en cuyo campo se sustancian las diferentes connotaciones en torno

53 Arist., EE, 1232a 14-15 
al honor, la dignidad y la valía ${ }^{54}$. En conclusión, la hermenéutica de la semnótes no solo nos descubre una ética del decoro, sino que apunta como un faro a la noción de dignidad que se forjó en la polis democrática. Aristóteles nos brinda una versión urbanizada de esta noción. La dignidad, para poder ser ejercida como tal, tiene que guardar el decoro. Todo un alegato contra los personajes que poblaban las comedias de Aristófanes, que siendo cualquier cosa menos decorosos, eran los encargados de custodiar la dignidad de la democracia.

\section{Fuentes antiguas y traducciones modernas}

CICERÓN: El Orador, texto revisado y traducido por Antonio Tovar y Aurelio R. Bujaldón, $2^{a}$ edición, Madrid: Consejo Superior de Investigaciones Científicas, 1992.

CICERÓN: Sobre los Deberes, trad. J. Guillén, Madrid: Ed. Alianza, 2001.

DEMÓSTENES: Demosthenis orationes, ed. W. Rennie, Oxford: Oxford University Press, 1931.

EURÍPIDES: Ifigenia en Áulide, traducción de Carlos García Gual, en Tragedias Vol. III, Madrid: Editorial Gredos, 1979.

TEOFRASTO: Caracteres, traducción de Elisa Ruiz García, en Teofrasto: Caracteres. Alcifrón: Cartas de pescadores, campesinos, parásitos y cortesanas, Madrid: Editorial Gredos, 1988.

\section{Traducciones de la Ética Eudemia}

Aristotelis Ethica Eudemia, edidit Adolphus Theodorus Hermannus Fritzschius, Ratibonae: G.I. Manz, 1851

Morale a Eudeme, traduite par J. Barthélemy-Saint Hilaire, Paris: Librairie Philosophique de Ladrange, 1856.

Magna Moralia. Ethica Eudemia. De Virtudibus et Vitiis, Translated into English under the editorship of W.D. Ross, London: Oxford University Press, 1915.

Athenian Constitution. Eudemian Ethics. Virtues and Vices, Translated by H. Rackham, Loeb Classical Library 285, Cambridge, MA: Harvard University Press, 1935.

Éthique á Eudème, introduction, traduction, notes et índices par Vianney Décarie, Paris: Librairie J. Vrin et Presses de l'Université de Montréal, 1978.

Eudemian Ethics, translated with commentary by Michael Woods, New York: Oxford University Press, 1982.

Eudemische Ethik, Übersetzt und kommentiert von Franz Dirlmeier (Aristoteles: Werke, Band 7), Berlin: Akademie Verlag, 1984.

Ética Nicomaquea. Ética Eudemia, introducción por Emilio Lledó Iñigo, traducción y notas por Julio Pallí Bonet, Madrid: Gredos, 1985.

Ética Eudemia, traducción, introducción y notas de Antonio Gómez Robledo, México, Universidad Nacional Autónoma de México, 1994.

54 Un intento en esta dirección en Ober, J. (2012), «Democracy’s Dignity», American Political Science Review, Vol. 106, nº 4, pp. 827-846. 
Ética Eudemia, introducción, traducción y notas de Carlos Megino Rodríguez, Madrid: Alianza Editorial, 2002.

Ética Eudemia. Grán Ética. Sobre las perfecciones morales y los vicios, introducción, traducción y notas de Alberto Medina González, Madrid: Ediciones Clásicas, 2007.

The Eudemian Ethics, Translated with an Introduction and Notes by Anthony Kenny, Oxford: Oxford University Press, 2011.

The Eudemian Ethics of Aristotle, Translated with Explanatory Comments by Peter L. P. Simpson, New Brunswick and London: Transaction Publishers, 2013.

Éthique á Eudème, traduction et présentation par Catherine Dalimier, Paris: ed. Flammarion, 2013.

\section{Traducciones de la Retórica}

Opera Omnia Graece, Vol. 4, Tr. Johannes Theophilus Buhle, Zweibrücken: Typographia Societatis, 1793.

Retórica, edición del texto con aparato crítico, traducción, prólogo y notas por Antonio Tovar, Madrid: Centro de Estudios Constitucionales, 1953.

Retórica, introducción, traducción y notas por Quintín Racionero, Madrid: Editorial Gredos, 1990.

On Rhetoric. A Theory of Civic Discourse, Newly Translated, with Introduction, Notes, and Appendices by George A. Kennedy, New York: Oxford University Press, 1991.

Opere. Volume decimo. Retorica. Poetica, Traduzione di Armando Plebe, Roma: Editori Laterza, 1992.

Retórica, introducción, traducción y notas de Alberto Bernabé, Madrid: Alianza Editorial, 1998.

Rhetoric, Übersetzt und erläutert von Christoff Rapp (Aristoteles: Werke, Band 4), Berlin: Akademie Verlag, 2002.

Retórica, versión de Arturo Ramírez Trejo, México: Universidad Nacional Autónoma de México, 2002.

\section{Diccionarios}

CHANTRAINE, P. (1968-1980), Dictionnaire etymologique de la langue grecque: histoire des mots, Paris: Éditions Klincksieck

LIDDELL, H. G. AND SCOTT, R. (1940): A Greek-English Lexicon, revised and augmented throughout by Sir Henry Stuart Jones, with the assistance of Roderick McKenzie, $9^{\text {a }}$ Edición, Oxford: Clarendon Press.

REAL ACADEMIA ESPAÑOLA (2014): Diccionario de la lengua española, 23ª ed., Madrid: Espasa.

VV.AA. (1997): Clave: Diccionario de uso del español actual, prólogo de Gabriel García Márquez, Madrid: Ediciones SM.

VV.AA: Diccionario Griego-Español (DGE) en línea, Consejo Superior de Investigaciones Científicas (CSIC), [http://dge.cchs.csic.es/]. 


\section{Bibliografía}

CERVANTES, M. (1998): Don Quijote de la Mancha, presentación y prólogo de Francisco Rico, Barcelona: Galaxia Gutenberg-Círculo de Lectores. (Obra original publicada en 1605-1615).

CHEVALIER, M. (1993): «Decoro y decoros», Revista de Filología Española, tomo LXXIII, $\mathrm{n}^{\mathrm{o}}$ 1/2, pp. 5-24. doi http://dx.doi.org/10.3989/rfe.1993.v73.i1/2.552.

COVARRUBIAS, S. (1979): Tesoro de la lengua castellana, Madrid: Turner. (Obra original publicada en 1611).

DEBES, R. (2009): «Dignity's Gauntlet», Philosophical Perspectives, Vol. 23, Ethics, pp. 45-78. doi: http://dx.doi.org/10.1111/j.1520-8583.2009.00161.x.

FORTENBAUGH, W. W. (1968): «Aristotle and the Questionable Mean-Dispositions», Transactions and Proceedings of the American Philological Association, Vol. 99. doi: http://dx.doi.org/10.2307/2935840.

GOTTLIEB, P. (2009): The Virtue of Aristotle's Ethics, Cambridge: Cambridge University Press. doi: https://doi.org/10.1017/CBO9780511581526.

HABERMAS, J. (2010): «El concepto de dignidad humana y la utopía realista de los derechos humanos», Diánoia, volumen LV, número 64, pp. 3-25. doi: http://dx.doi. org/10.21898/dia.v55i64.218.

KAPUST, D. (2012): «Cicerón: El decorum y la moralidad de la retórica», Praxis Filosófica Nueva Serie, $\mathrm{N}^{\mathrm{o}} 35$, pp. 257-282.

KENNY, A. (2016): The Aristotelian Ethics: A Study of the Relationship Between the Eudemian and Nicomachean Ethics of Aristotle, $2^{\mathrm{a}}$ Ed., Oxford: Oxford University Press. doi: http://dx.doi.org/10.1093/acprof:oso/9780198790938.001.0001.

LEBECH, M. (2009): On the Problem of Human Dignity: A Hermeneutical and Phenomenological Investigation, Würzburg: Königshausen \& Neumann.

NUSSBAUM, M. (1995): La fragilidad del bien. Fortuna y ética en la tragedia y la filosofía griega, traducción de Antonio Ballesteros, Madrid: Visor. (Obra original publicada en 1986).

OBER, J. (2012): «Democracy's Dignity», American Political Science Review, Vol. 106, nº 4, pp. 827-846. doi: 10.1017/S000305541200038X.

SULMASY, D. (2007): «Human Dignity and Human Worth», en: Malpas and Lickiss (eds.): Perspectives on Human Dignity. A Conversation, Dordrecht: Springer, pp. 9-18.

VALDÉS, J. (1969): Diálogo de la lengua, Madrid: Clásicos Castalia. (Obra original publicada en 1736). 